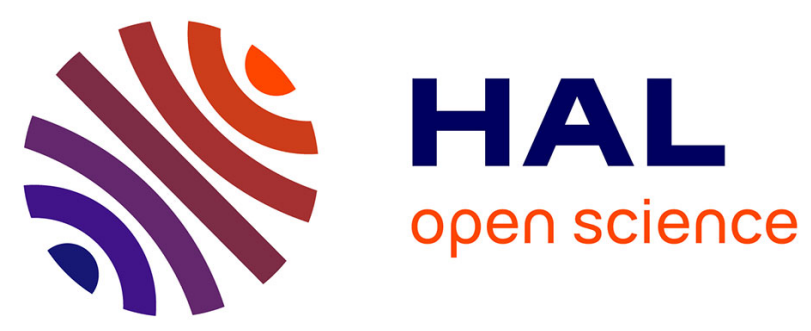

\title{
Study of ferroelectric/dielectric multilayers for tunable stub resonator applications at microwaves
}

\author{
Yonathan Corredores, Arnaud Le Febvrier, Xavier Castel, Ronan Sauleau, \\ Ratiba Benzerga, Stéphanie Députier, Maryline Guilloux-Viry, Ali \\ Mekadmini, Noham Martin, Gérard Tanné
}

\section{To cite this version:}

Yonathan Corredores, Arnaud Le Febvrier, Xavier Castel, Ronan Sauleau, Ratiba Benzerga, et al.. Study of ferroelectric/dielectric multilayers for tunable stub resonator applications at microwaves.

Thin Solid Films, 2014, 553, pp.109-113. 10.1016/j.tsf.2013.11.068 . hal-00911792

\section{HAL Id: hal-00911792 \\ https://hal.science/hal-00911792}

Submitted on 27 May 2014

HAL is a multi-disciplinary open access archive for the deposit and dissemination of scientific research documents, whether they are published or not. The documents may come from teaching and research institutions in France or abroad, or from public or private research centers.
L'archive ouverte pluridisciplinaire HAL, est destinée au dépôt et à la diffusion de documents scientifiques de niveau recherche, publiés ou non, émanant des établissements d'enseignement et de recherche français ou étrangers, des laboratoires publics ou privés. 


\title{
STUDY OF FERROELECTRIC/DIELECTRIC MULTILAYERS FOR TUNABLE STUB RESONATOR APPLICATIONS AT MICROWAVES
}

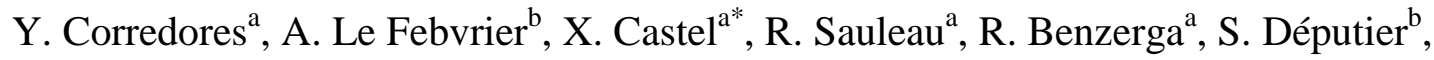

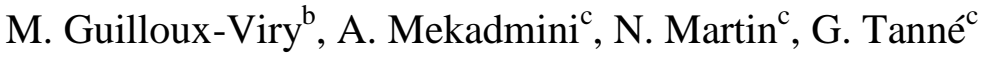 \\ ${ }^{a}$ IETR, UMR-CNRS 6164, IUT de Saint-Brieuc, 18 rue Henri Wallon, 22004 Saint-Brieuc \\ et 263 avenue du Général Leclerc, Université de Rennes 1, 35042 Rennes, France \\ ${ }^{b}$ ISCR, UMR-CNRS 6226, Université de Rennes 1, 263 avenue du Général Leclerc, \\ 35042 Rennes, France \\ ${ }^{c}$ Lab-STICC, UMR-CNRS 6285, Université de Bretagne Occidentale, 6 avenue Le Gorgeu, \\ 29238 Brest, France
}

\begin{abstract}
Tunable coplanar waveguide stub resonators deposited on various ferroelectric/dielectric heterostructures are studied in the $10-\mathrm{GHz}$ band. A frequency tunability up to $\sim 45 \%$ is achieved under a moderate biasing field $\left(E_{\text {bias }}<100 \mathrm{kV} / \mathrm{cm}\right)$ when the resonator is printed on $\mathrm{KTa}_{0.5} \mathrm{Nb}_{0.5} \mathrm{O}_{3}$ (KTN) ferroelectric thin film alone: this comes from the large permittivity agility of the KTN material ( $\varepsilon_{r(K T N)}$ varies from $\sim 700$ to $\sim 200$ ). Nevertheless this also leads to significant insertion loss due to the dielectric loss of the ferroelectric material itself $\left(\tan \delta_{r(K T N)} \approx 0.15-0.30\right.$ at $\left.10 \mathrm{GHz}\right)$. In this paper, an original route has been considered to reduce the device loss while keeping up a high frequency tunability. It consists in associating the KTN film with a dielectric film to elaborate ferroelectric/dielectric multilayers. The
\end{abstract}

\footnotetext{
* Corresponding author. Tel.: +332966096 53; fax: +33296609652.

E-mail address: xavier.castel@univ-rennes1.fr (X. Castel).
} 
$\mathrm{Bi}_{1.5} \mathrm{Zn}_{0.9} \mathrm{Nb}_{1.5} \mathrm{O}_{7-\delta}(\mathrm{BZN})$ oxide material is selected here for two main reasons, namely its low dielectric loss $\left(\tan \delta_{r(B Z N)} \approx 0.005-0.0075\right)$ and its moderate relative permittivity $\left(\varepsilon_{r(B Z N)} \approx 95\right.$ $125)$ at $12.5 \mathrm{GHz}$. The relevance of this approach is studied numerically and experimentally. We compare numerically two different heterostructures for which the ferroelectric film is grown on the dielectric film (KTN/BZN), or vice versa $(\mathrm{BZN} / \mathrm{KTN})$. A stub resonator printed on the most relevant heterostructure has been fabricated, and experimental data are discussed and compared to the numerical results.

Keywords: dielectric/ferroelectric heterostructure; multilayer; dielectric film; ferroelectric film; tunable resonator; microwave.

\section{Introduction}

Nowadays numerous wireless applications require advanced miniature and adaptive components or devices at microwaves, e.g. [1-4], especially to cope with the wide diversity of available communication standards. In particular reconfigurable filters, resonators and antennas, e.g. [5-7] are key building blocks of future radio front-ends. In this frame, ferroelectric oxides are promising candidates to design such devices [8-10] as their large relative permittivity ensures circuit miniaturization and is also controlled by an external static electric field $\left(E_{\text {bias }}\right)$. Moreover their deposition in thin films offers the ability to fabricate planar devices with low driving $E_{\text {bias }}$, easily integrated with planar circuits. The most popular ferroelectric materials are $\mathrm{Ba}_{\mathrm{x}} \mathrm{Sr}_{1-\mathrm{x}} \mathrm{Ti}_{\mathrm{x}} \mathrm{O}_{3}$ (BST) [11] and $\mathrm{PbZr}_{1-\mathrm{x}} \mathrm{Ti}_{\mathrm{x}} \mathrm{O}_{3}$ (PZT) [12]. In this work, the attention is focused on an alternative oxide, namely $\mathrm{KTa}_{1-\mathrm{x}} \mathrm{Nb}_{\mathrm{x}} \mathrm{O}_{3}(\mathrm{KTN})$, which exhibits strong potential for tunability [13].

The $\mathrm{KTa}_{0.5} \mathrm{Nb}_{0.5} \mathrm{O}_{3}$ composition $(\mathrm{x}=0.5)$ is selected here to reach the highest frequency tunability of the device under a moderate biasing $\left(E_{\text {bias }}<100 \mathrm{kV} / \mathrm{cm}\right)$. This composition 
exhibits a large relative permittivity $\varepsilon_{r(K T N)} \approx 700$, but also leads to significant dielectric loss $\left(\tan \delta_{r(K T N)} \approx 0.15-0.30\right.$ at $\left.10 \mathrm{GHz}\right) \quad[13,14]$. Three main solutions can be considered to overcome this drawback: (i) doping the KTN ferroelectric material in order to lower its intrinsic loss [15]; (ii) confining the KTN film only in specific regions of the device and to remove it in 'non-critical' areas [16]; and (iii) associating the KTN film with a low loss dielectric material to build ferroelectric/dielectric multilayers. The latter solution is investigated here.

The $\mathrm{Bi}_{1.5} \mathrm{Zn}_{0.9} \mathrm{Nb}_{1.5} \mathrm{O}_{7-\delta}$ oxide (BZN) has been selected due to its low dielectric loss at microwaves $\left(\tan \delta_{r(B Z N)} \approx 0.005-0.0075\right.$ at $\left.12.5 \mathrm{GHz}\right)[17,18]$. It also exhibits a moderate relative permittivity in this frequency band $\left(\varepsilon_{r(B Z N)} \sim 95-125\right)$. For the current study, BZN oxide is used as a pure dielectric material. Nonetheless it can exhibit tunable property, but only under very high bias field $\left(E_{\text {bias }}>1 \mathrm{MV} / \mathrm{cm}\right)[19]$.

The paper is organized as follows. After a description of the experimental details in Section 2, a numerical study comparing the performance of coplanar waveguide (CPW) stub resonators printed on both heterostructures (KTN/BZN and BZN/KTN) is provided in Section 3. The impact of the BZN thickness and its position in the heterostructures are studied in terms of tunability and global loss. The proposed fabrication process and the experimental results are discussed in Section 4, and the conclusions are drawn in Section 5.

\section{Experimental details}

2.1 Elaboration of KTN and BZN thin films

The $\mathrm{KTa}_{0.5} \mathrm{Nb}_{0.5} \mathrm{O}_{3}$ and $\mathrm{Bi}_{1.5} \mathrm{Zn}_{0.9} \mathrm{Nb}_{1.5} \mathrm{O}_{7-\delta}$ thin films have been deposited in a single run at $700^{\circ} \mathrm{C}$ by pulsed laser deposition under an oxygen pressure of $30 \mathrm{~Pa}$ on R-plane sapphire substrates $(10 \mathrm{~mm} \times 10 \mathrm{~mm} \times 0.5 \mathrm{~mm})$ using a $\mathrm{KrF}$ excimer laser $(\lambda=248 \mathrm{~nm})$ operating at $2 \mathrm{~Hz}$ with a laser fluence of $2 \mathrm{~J} / \mathrm{cm}^{2}$ and a distance of $55 \mathrm{~mm}$ between the substrate and the 
target. Note that a $60 \%$-potassium enriched target (in mol in form of $\mathrm{KNO}_{3}$ ) and a $10 \%$ bismuth $+40 \%$-zinc enriched target (in mol in form of $\mathrm{Bi}_{2} \mathrm{O}_{3}$ and $\mathrm{ZnO}$, respectively) were used for the $\mathrm{KTa}_{0.5} \mathrm{Nb}_{0.5} \mathrm{O}_{3}$ and $\mathrm{Bi}_{1.5} \mathrm{Zn}_{0.9} \mathrm{Nb}_{1.5} \mathrm{O}_{7-\delta}$ thin film elaboration respectively, to counterbalance the volatility of the potassium, bismuth and zinc elements during the deposition stages.

\subsection{Metallization}

Coatings of silver (Ag, $2 \mu$ m-thick) and titanium (Ti, $5 \mathrm{~nm}$-thick) were deposited one after another on the oxide films by RF magnetron sputtering technique at room temperature. The titanium film ensures strong adhesion of the silver metallization. The deposition chamber (Plassys MP 450S) contains two sputtering targets (75 $\mathrm{mm}$ in diameter): a titanium disc (99.995\% purity) and a silver disc $(99.999 \%$ purity). This configuration makes it possible to deposit the $\mathrm{Ag} / \mathrm{Ti}$ coating in a complete run without breaking vacuum. During deposition, a $\mathrm{RF}$ power of $150 \mathrm{~W}$ was supplied to the working target through an automatic matching network. The argon gas pressure (99.9996\% purity) into the sputtering chamber was adjusted by a mass flow controller (115 sccm for a total pressure of $1.07 \mathrm{~Pa})$. Sputtering rate has been calibrated for each target (Ag: $146 \mathrm{~nm} / \mathrm{min}$, Ti: $19 \mathrm{~nm} / \mathrm{min}$ ). The thickness of each layer is then controlled through the sputtering time.

\subsection{Chemical etching}

A standard photolithographic wet etching process was used to define the metallic patterns of the stub resonators. After metallization, the samples were spin-coated with a photosensitive resin layer (Microposit S1828 photo resist from Shipley). Then they were exposed to ultraviolet (UV) light through a photomask with the appropriate pattern (Karl Süss MJB3 mask aligner). After developing the exposed photoresist, the Ag and Ti coatings were etched 
in suitable chemical solutions at room temperature. The silver layer was etched in $\mathrm{HNO}_{3} / \mathrm{H}_{3} \mathrm{PO}_{4} / \mathrm{CH}_{3} \mathrm{COOH} / \mathrm{H}_{2} \mathrm{O}$ solution with ratio of $1: 4: 4: 1$ (v/v), the titanium layer in $\mathrm{HF} / \mathrm{H}_{2} \mathrm{O}$ solution with ratio of 3:97 (v/v).

\subsection{Characterizations, simulations and measurements}

X-ray diffraction (XRD) patterns were recorded with a D 8 Advanced Brüker AXS $(\theta-2 \theta$ configuration) equipped with a monochromatized $C u K \alpha_{1}$ radiation source. $2 \theta$ angle is swept from $10^{\circ}$ to $80^{\circ}$ by $0.01^{\circ}$ steps. Surface morphology of the oxide films was determined via field-emission scanning electron microscopy (FE-SEM) using a JEOL JSM 6310F system working at a low accelerating voltage $(7 \mathrm{kV})$. The thickness of oxide films was also measured by FE-SEM on cleaved sections.

Numerical simulations were carried out using the Finite Element Method (FEM) implemented in the commercial electromagnetic software ANSYS Ansoft HFSS ${ }^{\mathrm{TM}}$.

Measurements at microwaves were performed at room temperature in the frequency range from $1 \mathrm{GHz}$ to $20 \mathrm{GHz}$ using a vector network analyzer (37369A Wiltron) and a probe station after a Line-Reflect-Reflect-Match calibration. A maximum bias voltage of $120 \mathrm{~V}$ was applied on the device through bias tees (SHF-BT45 HV200) to isolate the vector network analyzer from the DC power supply. The resonance frequency of the CPW stub resonators was controlled by monitoring the external bias voltage. Gold wire bondings (length: $250 \mu \mathrm{m}$, diameter: $15 \mu \mathrm{m}$ ) were used to enforce the equipotential condition on the both CPW grounds and prevent from the excitation of parasitic slotline modes.

\section{Numerical simulations}

Two types of multilayers are compared numerically, namely the BZN/KTN heterostructure and the KTN/BZN one, as shown in Fig. 1. A quarter-wavelength open-ended CPW stub 
resonator fed by a transmission line (length: $8 \mathrm{~mm}$ ) is printed on each heterostructure (Figs. 1 and 2). The resonant frequency $F_{r}$ of the resonator (Eq. 1) depends on the stub length and the dielectric characteristics of the heterostructure:

$$
F_{r}=\frac{c}{4 L_{r} \sqrt{\varepsilon_{e f f}}}
$$

where $L_{r}, c$ and $\varepsilon_{e f f}$ are the stub length, the speed of light in vacuum, and the effective permittivity of the heterostructure on which the resonator is printed, respectively. The heterostructures are deposited on $\mathrm{Al}_{2} \mathrm{O}_{3}$ sapphire substrates (relative permittivity $\varepsilon_{s}=10$, and loss tangent $\tan \delta_{s}=10^{-4}$ at $10 \mathrm{GHz}$; thickness $t_{s}=0.5 \mathrm{~mm}$ ). The oxide films are characterized by the following parameters: for KTN: relative permittivity $\varepsilon_{r(K T N)}=700\left(E_{\text {bias }}=0\right)$ and 200 (when $E_{\text {bias }}$ is applied [14]); loss tangent $\tan \delta_{r(K T N)}=0.25$ [13]; thickness $t_{1}=600 \mathrm{~nm}$; for BZN: $\varepsilon_{r(B Z N)}=100, \tan \delta_{r(B Z N)}=10^{-2}$, and its thickness $t_{2}$ varies from $0 \mathrm{~nm}$ to $600 \mathrm{~nm}$. A silver metallization is used for the coplanar stub resonator (conductivity $\sigma_{A g}=6.1 \times 10^{7} \mathrm{~S} / \mathrm{m} \mathrm{[20]}$ and thickness $t_{m}=2 \mu \mathrm{m}$ ). The metallization thickness is three times larger than the skin depth value $(\delta=0.64 \mu \mathrm{m})$ at the operating frequency $(\sim 10 \mathrm{GHz})$. For simple and efficient numerical simulations, we considered that the relative permittivity of the whole KTN layer is modified under biasing.

The relevant parameters proposed to quantify the performance of the stub resonators in both configurations are the following: $(i)$ the frequency tunability $\left(T_{S}\right)$ defined as the relative variation of the resonant frequency $\left(F_{r}\right)$ under biasing $E_{\text {bias }}$ (Eq. 2); (ii) the global loss $\left(G L_{S}\right)$ computed at the resonance frequency; it includes all sources of loss in the device (Eq. 3); in this equation, $\left|S_{11}\right|$ and $\left|S_{21}\right|$ are magnitudes of the scattering parameters of the stub resonator; and (iii) the figure of merit $\left(F o M_{S}\right)$ quantifying the trade-off between tunability and global loss (Eq. 4); it is also computed at the resonance frequency $F_{r}$. 


$$
\begin{gathered}
T_{S}(\%)=\frac{\left|F_{r}\left(E_{\text {bias }}=0 \mathrm{kV} / \mathrm{cm}\right)-F_{r}\left(E_{\text {bias }}\right)\right|}{F_{r}\left(E_{\text {bias }}=0 \mathrm{kV} / \mathrm{cm}\right)} \times 100 \\
G L_{S}=1-\left|S_{11}\right|^{2}-\left|S_{21}\right|^{2} \\
F O M_{S}=\frac{T_{S}}{G L_{S}\left(F_{r}\right)}
\end{gathered}
$$

For the BZN/KTN/sapphire multilayer, the numerical results show that an increase of the BZN thickness reduces the frequency tunability of the stub resonator (Table 1) because the peculiar distribution of the electric field lines along the CPW stub leads to a lower interaction between the electromagnetic wave and the ferroelectric underlayer. Nonetheless the global loss for the configuration using a $200 \mathrm{~nm}$-thick BZN film is slightly reduced $\left(G L_{S}=0.68\right)$ while keeping a suitable tunability value $\left(T_{S}=45 \%\right)$. For comparison, the values obtained without the dielectric film are the following: $G L_{S}=0.71$ and $T_{S}=54 \%$. However the $F o M_{S}$ is lower with BZN (Table 1) because the decrease of the global loss does not compensate for the reduction of the tunability. Magnitude of the scattering parameters $S_{i j}$ of the stub resonator with and without the $200 \mathrm{~nm}$-thick BZN film are plotted in Fig. 3.

For the KTN/BZN/sapphire multilayer, increasing the BZN film thickness leads to a lower reduction in frequency tunability (Table 2) due to the stronger interaction between the electromagnetic wave and the ferroelectric layer. Almost the same frequency tunability $\left(T_{S}=51 \%\right)$ with an unchanged global loss $\left(G L_{S}=0.70\right)$ are obtained with a $200 \mathrm{~nm}$-thick BZN film. The corresponding figure of merit is also reduced $(F o M s=72$ against 76 without BZN film, Table 2). Magnitude of the scattering parameters $S_{i j}$ of the stub resonator with and without the BZN film (200 nm-thick) are similar to those computed with the BZN/KTN/sapphire heterostructure; they are not shown here for brevity. 


\section{Experimental results}

It was observed experimentally that a secondary (non-tunable) KTN pyrochlore phase crystallizes when the KTN film grows over the BZN film. The use of a suitable layer (like $\mathrm{KNbO}_{3}$ ) between $\mathrm{KTN}$ and $\mathrm{BZN}$ films could suppress this undesirable phase, but this would increase the number of interfaces and could damage the device properties due to diffusion phenomena. Therefore only the BZN/KTN/sapphire configuration was considered in practice.

A BZN (80 nm-thick)/KTN (600 nm-thick) oxide film was grown by pulsed laser deposition on R-plane sapphire substrate. According to XRD patterns, BZN and KTN films are both polycrystalline (ICCD Powder Diffraction File Cards No. 052-1770 for BZN and No. 07-2011 for KTN) with a (100) preferred orientation for the KTN layer (Fig. 4). The cross-section and planar views by FE-SEM demonstrate a columnar growth with a granular appearance of the sample surface at high magnification $(50,000 \times$, Fig. 5). Note that the interface between BZN and KTN is not visible in the picture. The thickness of the BZN film $(80 \mathrm{~nm})$ has been selected because $(i)$ it should not affect the frequency tunability of the resonator, and (ii) it should reduce the global loss of the device (see Section 3). Unfortunately a thickness of $80 \mathrm{~nm}$ cannot be simulated numerically due to the very large computing resource that would be needed. A reference sample made of a single 600 nm-thick KTN film deposited on R-plane sapphire substrate has been elaborated. As a reminder, the single layer is also polycrystalline and presents also mainly a (100) orientation [13].

Due to a slight overetching, the resonator fabrication leads to a central conductor width and gap of the stub close to $w_{r}=11 \mu \mathrm{m}$ and $g_{r}=17 \mu \mathrm{m}$. This corresponds to a maximum biasing field $E_{\text {bias }}$ equal to $71 \mathrm{kV} / \mathrm{cm}$. Magnitude of the measured scattering parameters $S_{i j}$ of the BZN/KTN/R-plane sapphire and KTN/R-plane sapphire (reference) heterostructures are represented in Fig. 6. A large variation of the resonance frequency under biasing (shift of the $\left|S_{21}\right|$ peak) is observed with the multilayer heterostructure: $F_{r}$ varies from $9.4 \mathrm{GHz}$ without 
biasing to $13.0 \mathrm{GHz}$ under $E_{\text {bias }}=71 \mathrm{kV} / \mathrm{cm}$. This corresponds to a frequency agility of $38 \%$ while the tunability of the reference prototype equals $43 \%$ (Table 3 ). Both configurations keep a reflection coefficient $S_{11}$ close to $-5 \mathrm{~dB}:\left|S_{11}\right|$ varies from $-7.0 \mathrm{~dB}\left(E_{\text {bias }}=0 \mathrm{kV} / \mathrm{cm}\right)$ to $4.8 \mathrm{~dB}\left(E_{\text {bias }}=71 \mathrm{kV} / \mathrm{cm}\right)$ at the resonance.

The global loss $\left(G L_{S}\right)$ has been computed (Table 3). As expected, $G L_{S}$ is lower for the BZN/KTN/R-plane sapphire heterostructure $\left(G L_{S}=0.65\right)$ than for the reference one $\left(G L_{S}=0.72\right)$ because of the presence of the low loss BZN layer underneath the resonator. For all these reasons, the $F o M_{S}$ of both configurations are very close: $F o M_{S}=58$ for the multilayer configuration against 60 for the reference under $E_{\text {bias }}=71 \mathrm{kV} / \mathrm{cm}$ (Table 3). The respective $\mathrm{FoM}_{S}$ versus biasing are plotted in Fig. 7: FoM $\mathrm{M}_{S}$ of the BZN/KTN/R-plane sapphire sample remains broadly similar to that of the reference.

\section{Conclusion}

The performance of miniaturized tunable coplanar stub resonators deposited on various ferroelectric/dielectric heterostructures have been studied numerically at microwaves. The resonators have been printed in practice on two types of samples: a BZN ( $80 \mathrm{~nm}$-thick)/KTN (600 nm-thick)/R-plane sapphire multilayer and a KTN (600 nm-thick)/ R-plane sapphire single layer. The first one has been elaborated in view of lowering the global loss of such devices while keeping a large tunability under moderate biasing, and the second serves as a reference. As predicted by numerical simulations, the global loss of the device can be effectively reduced thanks to the low loss dielectric layer underneath the resonator. But its presence slightly degrades the resonator tunability, which is still high considering the moderate applied electric field $(71 \mathrm{kV} / \mathrm{cm})$. This explains why the figures of merit of both configurations remain quite similar at $\sim 13 \mathrm{GHz}$ under maximum biasing $\left(E_{\text {bias }}=71 \mathrm{kV} / \mathrm{cm}\right)$ : 58 for the BZN/KTN/R-plane sapphire multilayer and 60 for the KTN/R-plane single layer. 


\section{Acknowledgements}

The authors acknowledge the CMEBA for SEM observations.

\section{References}

[1] K. Chang and L.-H. Hsieh, Microwave Ring Circuits and Related Structures, $2^{\text {nd }}$ Ed., John Wiley \& Sons, Inc, Hoboken, New Jersey, 2004.

[2] D.B. Cruickshank, Microwave Materials for Wireless Applications, $1^{\text {st }}$ Ed., Artech House, Boston, 2011.

[3] F. Venneri, S. Costanzo, G. Di Massa, A. Borgia, P. Corsonello, M. Salzano, Proceedings of $6^{\text {th }}$ European Conference on Antennas and Propagation (EUCAP), Prague, Czech Republic, 2012, p. 2628.

[4] Y. Tawk, J. Costantine, C.G. Christodoulou, IEEE Antennas Wirel. Propag. Lett. 11 (2012) 716.

[5] J.-H. Lim, G.-T. Back, Y.-I. Ko, C.-W. Song, T.Y. Yun, IEEE Trans. Antennas Propag. 58 (2010) 2404.

[6] L. Pelliccia, S. Bastioli, F. Casini, R. Sorrentino, Proceedings of $40^{\text {th }}$ European Microwave Week (EuMC), Paris, France, 2010, p. 1126.

[7] M. Sazegar, Y. Zheng, H. Maune, C. Damm, X. Zhou, J. Binder, R. Jakoby, IEEE Trans. Microw. Theory Tech. 59 (2011) 1265.

[8] A.K. Tagantsev, V.O. Sherman, K.F. Astafiev, J. Venkatesh, N. Setter, J. Electroceramics 11 (2003) 5.

[9] S. Kasap, P. Capper, Handbook of Electronic and Photonic Materials, Springer Science, Inc., New York, 2006.

[10] N. Setter, D. Damjanovic, L. Eng, G. Fox, S. Gevorgian, S. Hong, A. Kingon, H. Kohlstedt, N.Y. Park, G.B. Stephenson, I. Stolitchnov, A.K. Taganstev, D.V. Taylor, T. Yamada, S. Streiffer, J. Appl. Phys. 100 (2006) 051606. 
[11] S. Gevorgian, Ferroelectrics in Microwave Devices Circuits and Systems, $1^{\text {st }}$ Ed., Springer-Verlag, London, 2009.

[12] S.S. Bedair, J.S. Pulskamp, C.D. Meyer, M. Mirabelli, R.G. Polcawich, B. Morgan, IEEE Electron Device Lett. 33 (2012) 1483.

[13] Q. Simon, Y. Corredores, X. Castel, R. Benzerga, R. Sauleau, K. Mahdjoubi, A. Le Febvrier, S. Députier, M. Guilloux-Viry, L. Zhang, P. Laurent, G. Tanné, Appl. Phys. Lett., 99 (2011) 092904.

[14] V. Laur, A. Moussavou, G. Tanné, P. Laurent, V. Bouquet, S. Députier, M. GuillouxViry, F. Huret, Proceedings of International Microwave Symposium (IMS), Honolulu, HI, 2007, p. 2059.

[15] Q. Simon, V. Bouquet, W. Peng, J.-M. Le Floch, F. Houndonougbo, S. Députier, S. Weber, A. Dauscher, V. Madrangeas, D. Cros, M. Guilloux-Viry, Thin Solid Films, 517 (2009) 5940.

[16] Y. Corredores, Q. Simon, X. Castel, R. Benzerga, R. Sauleau, K. Mahdjoubi, A. Le Febvrier, S. Députier, M. Guilloux-Viry, L. Zhang, P. Laurent, G. Tanné, Proceedings of $6^{\text {th }}$ European Conference on Antennas and Propagation (EUCAP), Prague, Czech Republic, 2012, p. 3591.

[17] K. Sudheendran, M. Ghanashyam Krishna, K.C. James Raju, Appl. Phys. A: Mater. Sci. Process. 95 (2009) 485.

[18] J.C. Nino, M.T. Lanagan, C.A. Randall, J. Appl. Phys. 89 (2001) 4512.

[19] A.-K. Tagantsev, J. Lu, S. Stemmer, Appl. Phys. Lett. 86 (2005) 032901.

[20] W.M. Haynes, Handbook of Chemistry \& Physics, $93^{\text {rd }}$ Ed., CRC Press LLC, Boca Raton, 2012-2013. 
$\underline{\text { Table } 1}$

\begin{tabular}{cccccc}
\hline \multirow{3}{*}{ BZN thickness $(\mathrm{nm})$} & \multicolumn{2}{c}{$F_{r}(\mathrm{GHz})$} & & \\
\cline { 2 - 5 } & $\varepsilon_{r(\mathrm{KTN})}=700$ & $\varepsilon_{r(\mathrm{KTN})}=200$ & & & \\
& 8.9 & 13.7 & 54 & 0.71 & 76 \\
\hline 0 & 9.1 & 13.2 & 45 & 0.68 & 66 \\
200 & 9.1 & 12.9 & 42 & 0.68 & 61 \\
300 & 9.0 & 12.7 & 41 & 0.68 & 61 \\
400 & 9.0 & 12.6 & 40 & 0.68 & 59 \\
500 & 8.9 & 12.4 & 39 & 0.67 & 59 \\
600 & & & & & \\
\hline
\end{tabular}

Table 1. Resonance frequency $\left(F_{r}\right)$, frequency tunability $\left(T_{S}\right)$, global loss $\left(G L_{S}\right)$ and figure of merit $\left(F o M_{S}\right)$ of the BZN/KTN (600 nm-thick)/sapphire configuration vs. BZN film thickness - Numerical results 
$\underline{\text { Table } 2}$

\begin{tabular}{|c|c|c|c|c|c|}
\hline \multirow{2}{*}{ BZN thickness (nm) } & \multicolumn{2}{|c|}{$F_{r}(\mathrm{GHz})$} & \multirow{2}{*}{$T_{S}(\%)$} & \multirow{2}{*}{$G L_{S}$} & \multirow{2}{*}{ FoM $_{S}$} \\
\hline & $\varepsilon_{r(\mathrm{KTN})}=700$ & $\varepsilon_{r(\mathrm{KTN})}=200$ & & & \\
\hline 0 & 8.9 & 13.7 & 54 & 0.71 & 76 \\
\hline 200 & 8.7 & 13.1 & 51 & 0.70 & 72 \\
\hline 300 & 8.8 & 12.9 & 47 & 0.69 & 68 \\
\hline 400 & 8.7 & 12.6 & 45 & 0.69 & 65 \\
\hline 500 & 8.6 & 12.4 & 44 & 0.68 & 65 \\
\hline 600 & 8.5 & 12.3 & 45 & 0.68 & 66 \\
\hline
\end{tabular}

Table 2. Resonance frequency $\left(F_{r}\right)$, frequency tunability $\left(T_{S}\right)$, global loss $\left(G L_{S}\right)$ and figure of merit $\left(F_{o M}\right)$ of the KTN (600 nm-thick)/BZN/sapphire configuration vs. BZN film thickness - Numerical results 
$\underline{\text { Table } 3}$

\begin{tabular}{|c|c|c|c|c|c|}
\hline \multirow{2}{*}{ BZN thickness (nm) } & \multicolumn{2}{|c|}{$F_{r}(\mathrm{GHz})$} & \multirow[b]{2}{*}{$T_{S}(\%)$} & \multirow{2}{*}{$G L_{S}$} & \multirow{2}{*}{ FoM $_{S}$} \\
\hline & $E_{\text {bias }}=0 \mathrm{kV} / \mathrm{cm}$ & $E_{\text {bias }}=71 \mathrm{kV} / \mathrm{cm}$ & & & \\
\hline 0 & 9.5 & 13.6 & 43 & 0.72 & 60 \\
\hline 80 & 9.4 & 13.0 & 38 & 0.65 & 58 \\
\hline
\end{tabular}

Table 3. Resonance frequency $\left(F_{r}\right)$, frequency tunability $\left(T_{S}\right)$, global loss $\left(G L_{S}\right)$ and figure of merit $\left(F_{o M_{S}}\right)$ of stub resonators printed on the BZN (80 nm-thick)/KTN(600 nmthick)/R-plane sapphire multilayer and $\mathrm{KTN}(600 \mathrm{~nm}$-thick)/R-plane single layer (reference) - Measurements 
$\underline{\text { Figure } 1}$
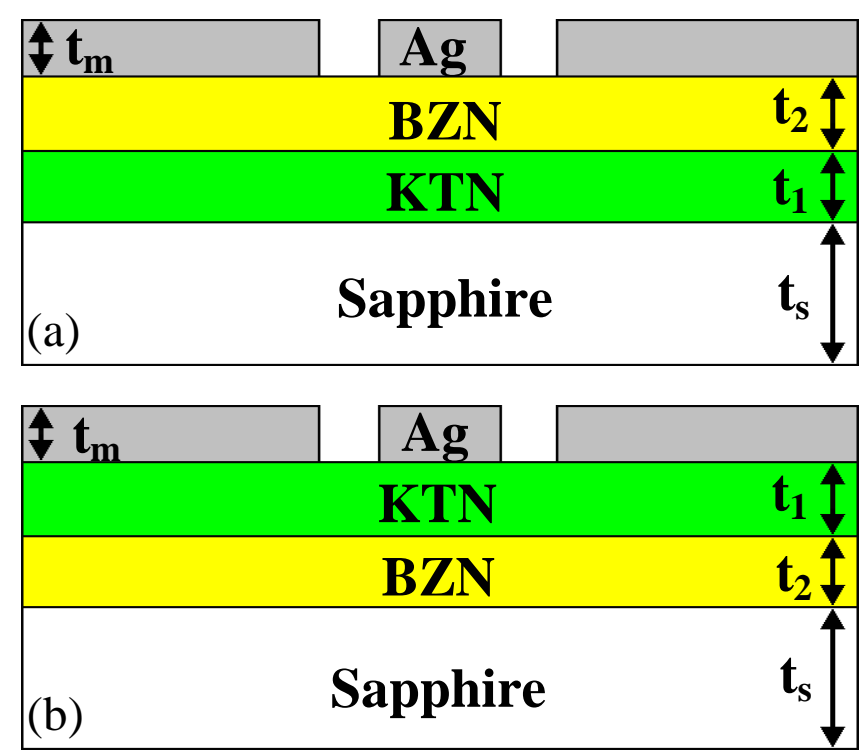

Fig. 1. Cross-sectional view of the coplanar stub resonators: (a) Ag/BZN/KTN/sapphire and (b) Ag/KTN/BZN/sapphire 
$\underline{\text { Figure } 2}$

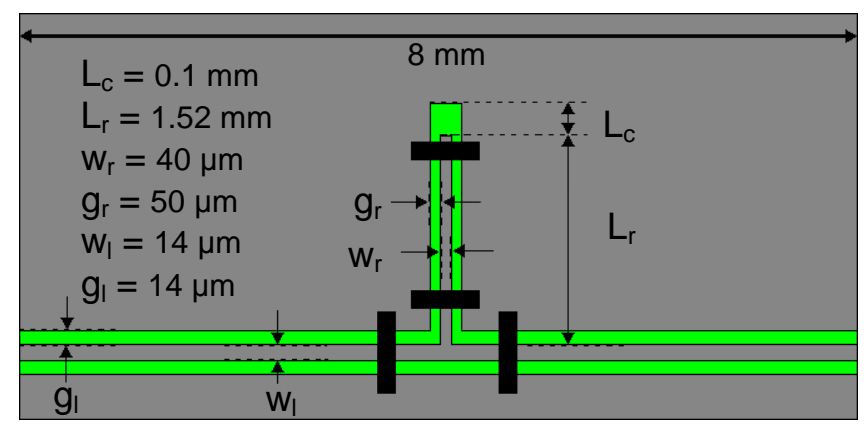

Fig. 2. Layout and dimensions of the coplanar stub resonator (top view). In grey: silver metallization; in green: oxide multilayer. Black rectangles symbolize gold wire bondings 


\section{Figure 3}
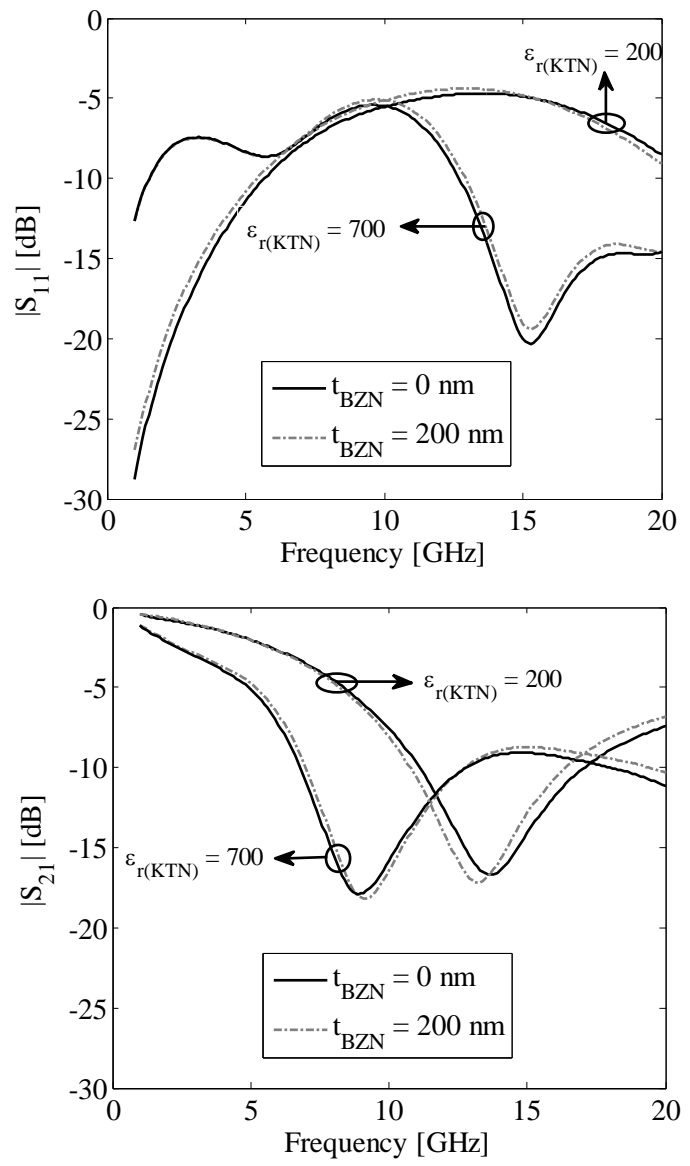

Fig. 3. Computed scattering parameters $\left|S_{i j}\right|$ (magnitude) of stub resonators printed on BZN(200 nm-thick)/KTN(600 nm-thick)/sapphire and KTN(600 nm-thick)/sapphire with $\varepsilon_{r(\mathrm{KTN})}$ varying from 700 to 200 
$\underline{\text { Figure } 4}$

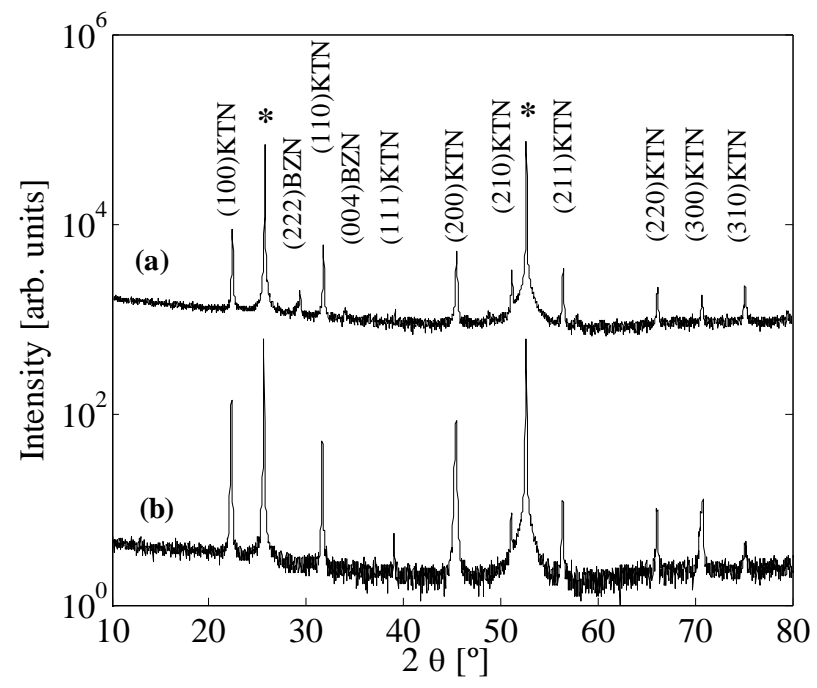

Fig. 4. $\theta-2 \theta$ XRD patterns of the $\mathrm{BZN}(80 \mathrm{~nm}$-thick $) / \mathrm{KTN}(600 \mathrm{~nm}$-thick $) / \mathrm{R}$-plane sapphire multilayer (a) and the $\mathrm{KTN}(600 \mathrm{~nm}$-thick)/R-plane sapphire single layer (b) as reference. The asterisks $(*)$ are related to the R-plane sapphire substrate 
$\underline{\text { Figure } 5}$

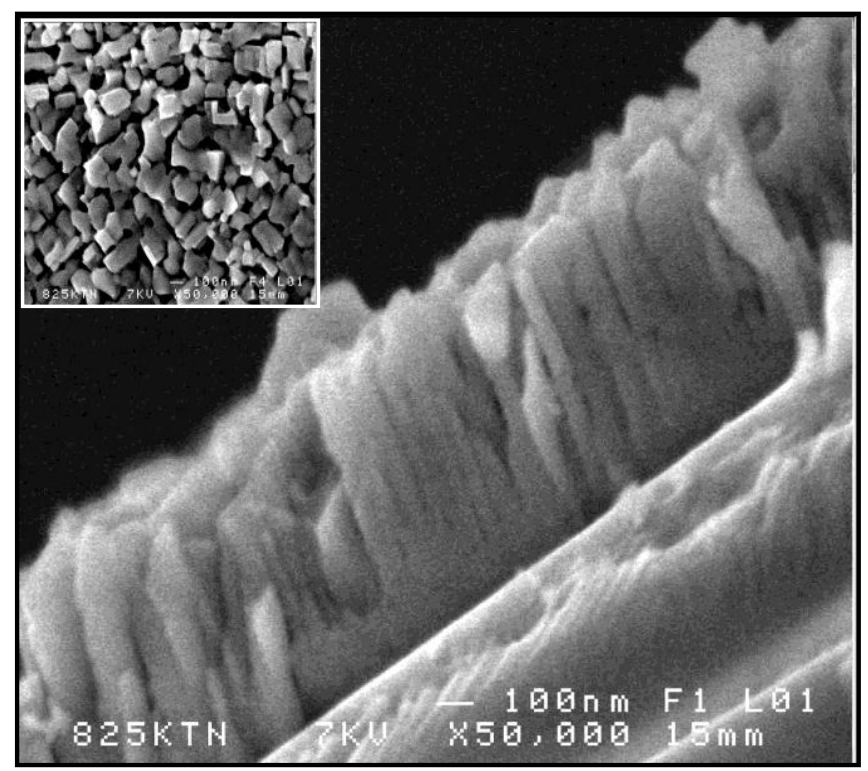

Fig. 5. FE-SEM cross-section and planar views of the BZN(80 nm-thick)/KTN(600 nmthick)/R-plane sapphire multilayer 
$\underline{\text { Figure } 6}$
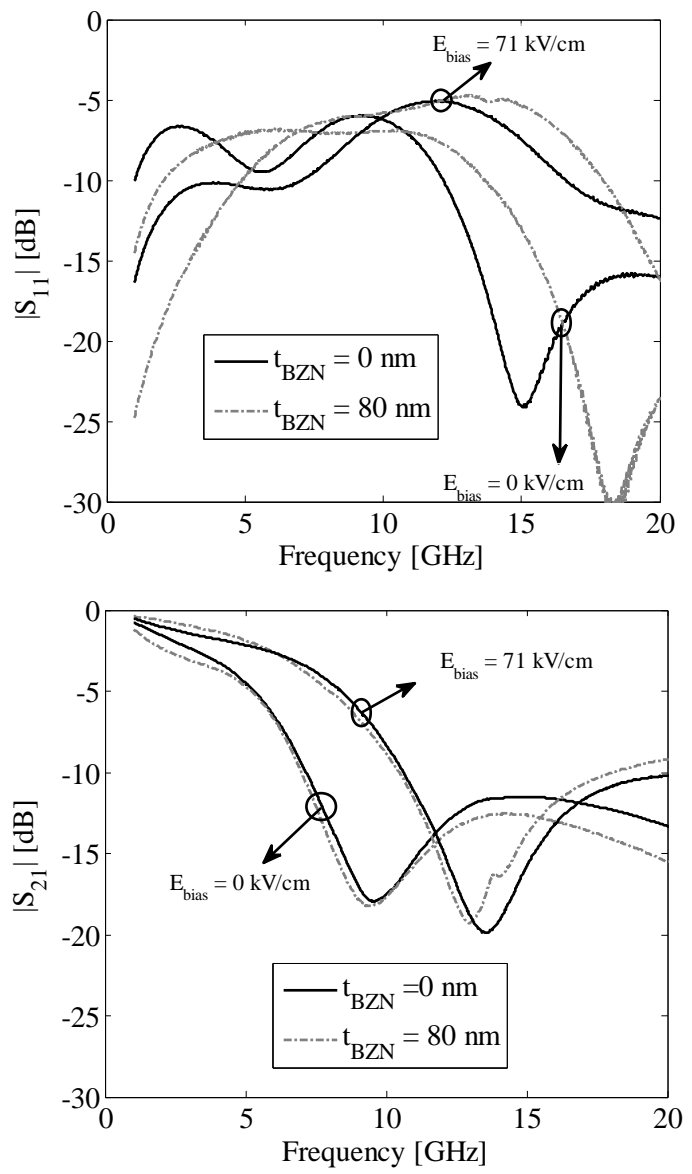

Fig. 6. Measured scattering parameters $\left|S_{i j}\right|$ (magnitude) of stub resonators printed on $\mathrm{BZN}(200 \mathrm{~nm}$-thick)/KTN(600 nm-thick)/sapphire and KTN(600 nm-thick)/sapphire (reference), with and without biasing $\left(E_{\text {bias }}\right)$ 
Figure 7

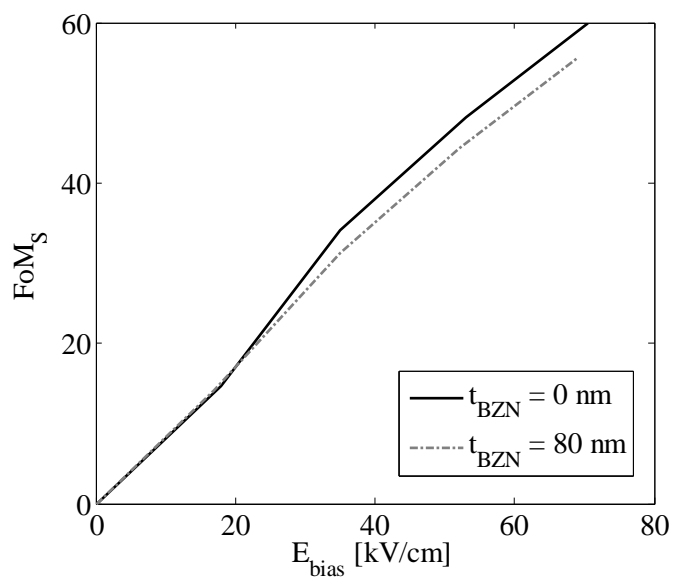

Fig. 7. $F_{o M_{S}}$ vs. $E_{\text {bias }}$ for stub resonators printed on $\mathrm{BZN}(200 \mathrm{~nm}$-thick $) / \mathrm{KTN}(600 \mathrm{~nm}$ thick)/R-plane sapphire and KTN(600 nm-thick)/R-plane sapphire (reference) 